\title{
Coulisses
}

Revue de théâtre

12| Printemps 1995

Varia

\section{Le ghetto de Térézin}

\section{Elisabeth Pastwa}

\section{(2) OpenEdition}

Journals

Édition électronique

URL : http://journals.openedition.org/coulisses/3393

DOI : $10.4000 /$ coulisses.3393

ISSN : 2546-9460

\section{Éditeur}

Presses universitaires de Franche-Comté

\section{Édition imprimée}

Date de publication : 1 mai 1995

Pagination : 61-63

ISSN : 1150-594X

\section{Référence électronique}

Elisabeth Pastwa, «Le ghetto de Térézin », Coulisses [En ligne], 12 | Printemps 1995, mis en ligne le 15 mars 2019, consulté le 31 octobre 2019. URL : http://journals.openedition.org/coulisses/3393 ; DOI : 10.4000/coulisses.3393

Ce document a été généré automatiquement le 31 octobre 2019

Coulisses 


\title{
Le ghetto de Térézin
}

\author{
Elisabeth Pastwa
}

1 Lors de la conférence du 20 janvier 1942, Reinhard Heydrich déclare avoir les pleins pouvoirs pour exécuter «la Solution Finale » - l'extermination des Juifs.

A la tête du protectorat de Bohème, il va faire de Terezin (Theresienstadt), petite ville de garnison dotée d'une forteresse, un ghetto. Ce ghetto est destiné d'abord

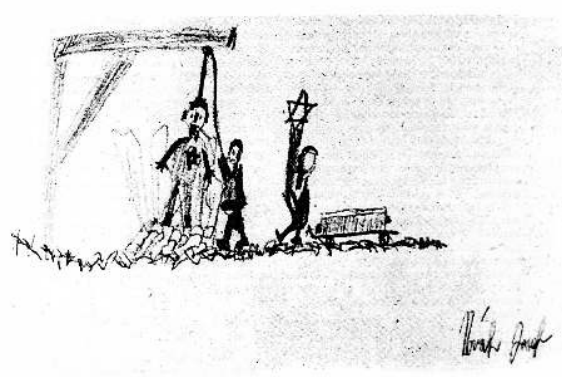
aux Juifs âgés et tout particulièrement à ceux qui au cours de la première guerre mondiale se sont illustrés au service de l'Allemagne. Il est constitué au printemps 1942. A ces Juifs méritants s'ajoutent un certain nombre de personnalités de l'intelligentsia dont aurait pu s'inquiéter l'opinion internationale.

La petite ville, évacuée de sa population initiale, accueillera 140000 Juifs dont la plupart sont Tchèques (73000), quelques centaines de Juifs danois et luxembourgeois, et en plus grand nombre des Allemands et des Autrichiens : une population dix fois supérieure à celle d'origine. Les conditions de vie sont extrêmement difficiles.

Je me souviens que maman marquait sur notre ration de pain la part à laquelle nous avions droit chaque jour; elle voulait s'assurer que nous en aurions assez pour la semaine. Mais, souvent, c'était difficile. Quand les douleurs de la faim étaient trop aiguës, à regret, elle entamait légèrement la part du pain du lendemain.

Je suis une étoile, Inge Auerbacher ${ }^{1}$

2 Les plus valides sont soumis au travail dans des kommandos extérieurs: mines, briqueteries, chemins de fer. 33000 personnes décédèrent au ghetto échappant à une autre mort, le gazage au camp d'Auschwitz.

On obligeait la plupart des hommes du camp à travailler. Des femmes étaient choisies pour fendre du mica, un produit dont les nazis se servaient pendant la guerre... Le premier travail de maman fut de laver le linge des malades atteints du typhus. Un jour, elle trouva un grand tas de ce qui semblait être des draps sales. 
Quand elle essaya de les ramasser, elle constata avec horreur que ces draps dissimulaient des morts. Les prisonniers mouraient comme des mouches à Terezin.

Je suis une étoile, Inge Auerbacher

3 A compter de janvier 1943, sur ordre de Kaltenbrunner qui succède à Heydrich, 88200 sont déportés à Auschwitz. De septembre à octobre 1944 ce sont 18400 hommes, femmes et enfants qui s'entassent dans 44 convois pour être presque tous gazés à l'arrivée. En mai 1945, il ne reste que 9000 fantômes pris en charge par la Croix Rouge internationale après le départ des nazis.

Nous vivions jour et nuit dans la peur que notre tour arrive... Les malheureux prisonniers sélectionnés recevaient un numéro qu'ils accrochaient autour de leur cou et devaient ensuite se réunir dans un bâtiment spécial. De là, on les faisait monter de force dans un wagon à bestiaux dont les portes étaient verrouillées...

Je suis une étoile, Inge Auerbacher

4 Mais ce n'est ni cette litanie de chiffres, ni ces comptes et ces décomptes confirmant l'industrie de mort mise en place par Hitler, qui fait que l'on parle de Terezin.

5 C'est un lieu où souffle, malgré les difficultés du quotidien, l'esprit: créations musicales, théâtrales seront les principales formes de résistance à l'avilissement. Les nombreux artistes juifs tchèques et d'Europe centrale incarcérés au ghetto de Terezin bravent les interdits pour garder leur raison de vivre. Non seulement on joue Schönberg, Mendelssohn ou Malher (tous proscrits parce que juifs) mais on crée : spectacles de cabaret où l'on ironise autour d'une carte d'alimentation, opéra pour enfants "Brundibar", pièces pour orchestre. Des ensembles se forment, chorales, jazzband, orchestres, décimés au fur et à mesure des convois, recréés quitte à remplacer le violon par l'accordéon.

6 Ce foisonnement (une cinquantaine d'œuvres ont été créées à Terezin) n'échappe pas à la direction du camp. Cela sert même d'outil de propagande lors du tournage à l'été 44 d'un film « Hitler fait cadeau d'une ville aux juifs».

7 Pour contrecarrer les rumeurs concernant le sort des Juifs, Goebbels imagine de faire tourner un film au ghetto de Terezin. Entreprise machiavélique qui met en scène les musiciens du ghetto, dans un cadre embelli pour la circonstance, avec pour caution la visite de la Croix Rouge. Ce film restera inachevé et ne sera jamais diffusé. Une copie a été acquise par le Musée de la Résistance et de la Déportation de Besançon.

Tout est prêt pour l'inspection de la Croix-Rouge,

Notre existence même est une illusion...

On a remplacé les numéros de blocs par des plaques de rues, ...

Nous devons même apprendre des phrases mises au point...

Un pavillon des enfants a été installé pour faire impression, ...

Il y a aussi une école, où nous n'allons jamais...

Bientôt, il ne restera plus trace de tout cela...

Dès que la commission est hors de vue,

Nous devons de nouveau nous soumettre à la tyrannie.

Bientôt, il y aura une nouvelle sélection...

Je suis une étoile, Inge Auerbacher

8 Le protectorat resta sous contrôle allemand jusqu'à la signature de la capitulation. Le dernier rapport du commandant de Terezin date du 5 mai et les troupes soviétiques n'entrèrent au ghetto que le 9 mai 1945. 


\section{BIBLIOGRAPHIE}

Ouvrages :

- HILBERG (Raul), La destruction des Juifs d'Europe, Paris, Fayard, 1988

- ASSOCIAZIONE NAZIONALE EX DEPORTATI POLITICI NEI CAMPI NAZISTI, Terezin : disegni e poesi dei bambini del campo di sterminio, Associazione Versiliese Italie/Tchécoslovaquie, n.d.

- AUERBACHER (Inge), Je suis une étoile : une enfant de l'holocauste, Paris, Seuil, 1989

- JACOT (Michael), Les Enfants de Terezin, Paris, Flammarion, 1974

- KARA (Joza), La Musique de Terezin : 1941-1945, Paris, Gallimard, 1993

Articles :

- KREISLER (Jacques), « Un ghetto pas comme les autres : Terezin et la musique », B.B.B. Infos, $n^{\circ} 6$

- MERIGAUD (Bernard), « Terezin : la musique contre l'horreur au camp de la mort » in Télérama, $\mathrm{n}^{\circ}$ 2267, 23 juin 1993

- SCHNEIDER (Michel), « La musique au lieu de la mort », in : Temps modernes, mai 1993

Autre :

- Der Fuhrer schenkt den Juden eine Stadt (fragment), VHS/SECAM, $15 \mathrm{mn}$

\section{NOTES}

1. 'Née à Kippenheim, en Allemagne, a été emprisonnée dans le camp de Terezin en Tchécoslovaquie de 1942 à 1945. En 1946, elle émigre aux Etats-Unis et vit depuis à New York.

\section{AUTEUR}

\section{ELISABETH PASTWA}

Conservateur du Musée de la Résistance et de la déportation de Besançon 